\author{
Media Publikasi Promosi Kesehatan Indonesia \\ The Indonesian Journal of Health Promotion
}

\title{
Strategi Promosi Kesehatan Terhadap Upaya Peningkatan Pengetahuan Pengelola Kantin Sehat
}

\section{Health Promotion Strategy Against Knowledge Improvement Efforts Of Healthy Canteen's Management}

\author{
${ }^{\left({ }^{*}\right)}$ Putri Permatasari, ${ }^{(2)}$ Sharadea \\ ${ }^{(1,2)}$ Program Studi Kesehatan Masyarakat FIKES UPN Veteran Jakarta, Indonesia \\ ${ }^{(*)} \frac{\text { ppermatasari8@gmail.com }}{\text { (") Corresponding Author }}$
}

\begin{abstract}
Abstrak
Kantin merupakan tempat atau bangunan dimana segenap warga sekitar lingkunganya dapat membeli pangan jajanan, baik berupa pangan siap saji maupun pangan olahan. Kantin sekolah mempunyai peranan yang penting dalam mewujudkan pesan-pesan kesehatan dan dapat menentukan perilaku makan sehari-hari melalui penyediaan makanan jajanan di sekolah. Pada tahun 2014 terjadi kasus keracunan makanan di berbagai wilayah Indonesia disebabkan oleh pangan jajanan sebanyak 15 insiden dengan korban 468 korban. Desain penelitian yang diterapkan adalah dengan pendekatan kuantitatif penelitian untuk melihat perbedaan sebelum intervensi-sesudah intervensi. Teknik pengambilan sampel dilakukan secara total sampling atau seluruh populasi pengelola kantin di UPN Veteran Jakarta. Pengumpulan data menghasilkan data primer dengan alat bantu kuesioner. Pengolahan data menggunakan uji wilcoxon untuk membandingkan nilai rata-rata pengetahuan kantin sehat sebelum intervensi (1,00,) sesudah intervensi $(2,00)$, pengetahuan hygiene perorangan sebelum intervensi $(1,78)$ sesudah intervensi $(2,00)$, pengetahuan sanitasi makanan sebelum intervensi $(1,81)$ sesudah intervensi $(2,00)$, dan pengetahuan gizi seimbang sebelum intervensi $(1,72)$ sesudah intervensi (2,00). Hasil penelitian menunjukan nilai signifikansi sebesar 0,000, 0,008, 0,014 dan 0,003. Kesimpulannya yaitu terdapat pengaruh promosi kesehatan terhadap peningkatan pengetahuan pengelola kantin yang meliputi kantin sehat, hygiene perorangan, sanitasi makanan, dan gizi seimbang.
\end{abstract}

Kata Kunci : Promosi Kesehatan; Pengetahuan; Kantin Sehat; Pengelola Kantin

\begin{abstract}
Canteen is a place or a building where all residents around the neighborhood can buy food snacks, both in the form of ready-toeat food and processed foods. School canteen has an important role in realizing health messages and can determine the behavior of daily meals through the provision of food snacks in schools. In the year 2014 cases of food poisoning in various parts of Indonesia caused by food snacks as much as 15 incidents with 468 victims. One strategy used is the provision of interventions in the form of health promotion. This study was conducted to assess the effect of health promotion on the knowledge of healthy canteen management at UPN Veteran Jakarta in 2018. The design of the applied research is with quantitative approach to see the difference before intervention-after intervention. The sampling technique was conducted in total sampling or entire population of canteen management at UPN Veteran Jakarta. Data collection yields primary data with questionnaires. Data processing used a wilcoxon test to compare the mean value of healthy canteen knowledge before intervention (1.00,) after intervention (2.00), knowledge of individual hygiene before intervention (1.78) after intervention (2.00), sanitizing knowledge food before intervention $(1,81)$ after intervention (2.00), and knowledge of balanced nutrition before intervention (1.72) after intervention (2.00). The results showed significance values of 0.000, 0.008, 0.014 and 0.003 . The conclusion is that there is influence of health promotion to increase of canteen management knowledge which include healthy canteen, individual hygiene, food sanitation, and balanced nutrition.
\end{abstract}

Keywords: Health Promotion, Knowledge, Healty Canteen, Canteen Management 


\section{PENDAHULUAN}

Kantin merupakan tempat atau bangunan dimana segenap warga sekitar lingkunganya dapat membeli pangan jajanan, baik berupa pangan siap saji maupun pangan olahan (1). Menurut Peraturan Gubernur Provinsi Daerah Ibu Kota Jakarta Nomor 140 Tahun 2013 tentang standar penyelenggaraan kantin sekolah sehat mendeskripsikan, kantin sekolah adalah tempat atau bangunan yang berada di lingkungan sekolah, sebagai usaha penyediaan pangan jajanan yang dilengkapi dengan peralatan dan perlengkapan untuk proses pengolahan, penyimpanan dan penyajian pangan jajanan (2). Kantin sekolah mempunyai peranan yang penting dalam mewujudkan pesan-pesan kesehatan dan dapat menentukan perilaku makan sehari-hari melalui penyediaan makanan jajanan di sekolah (1). Kantin sekolah dapat menyediakan makanan sebagai pengganti makan pagi dan makan siang di rumah serta camilan dan makanan yang sehat, aman dan bergizi (3).

Makanan yang sehat, aman dan bergizi adalah makanan yang mengandung zat gizi yang diperlukan seorang anak untuk dapat hidup sehat. Makanan tersebut harus bersih, tidak kadaluarsa, dan tidak mengandung bahan kimia maupun mikroba berbahaya bagi kesehatan (4). Selain itu makanan juga tidak boleh terkontaminasi oleh bakteri yang berasal dari orang yang mengelolanya, agar makanan tidak menjadi sumber penyakit. ${ }^{(4)}$ Makanan yang terkontaminasi dapat menyebabkan penyakit bawaan makanan (foodborne disease) seperti penyakit diare, hepatitis A, tipus, radang tenggorokan, disentri dan lain-lain (5). Menurut laporan Riset Kesehatan Nasional (RISKESDAS) tahun 2013 penyakit diare di Indonesia memiliki prevalensi sebesar 3,5 persen. Sedangkan penyakit hepatitis A di Indonesia terjadi sebesar 19,3 persen dari seluruh penduduk. Hal yang senada dengan apa yang dikumukakan oleh (McSwane,(2014), bahwa faktor yang berpengaruh terhadap kejadian foodborne diseasekarena ketidaksesuaian suhu, rendahnya praktik higiene perorangan, kontaminasi mikroorganisme, buruknya sanitasi lingkungan pengolahan, ketidaktepatan cara pengolahan, serta makanan berasal dari sumber yang berisiko (6).

Pengelola kantin memiliki tanggung jawab dalam ketersediaan makanan yang sehat, aman dan bergizi untuk di konsumsi setiap konsumennya. Serta menjadi peran utama dalam pemilihan makanan (6). Penelitian yang dilakukan oleh Zeviara Adhisty (2014) mengemukakan bahwa penilaian kantin sehat pangan jajanan anak sekolah di kota Depok terdapat sebelas kantin yang menunjukkan kantin tidak sehat karena masih banyak mengandung cemaran bakteri dan bahan berbahaya. Menurut Adhisty (2014), bahwa sebelas kantin ini masih perlu pembinaan dari keseluruhan warga didalam sekolahnya, baik sekolah maupun pengelola kantin. Salah satu faktor masih terdapat kantin tidak sehat yaitu rendahnya pengetahuan pengelola kantin (7).

Kantin yang sehat menjadi syarat utama yang harus dimiliki baik sekolah maupun universitas. Pengelola kantin sehat harus memiliki pengetahuan mengenai gizi seimbang, cara pengolahan pangan yang baik, keamanan pangan dan praktek higiene perorangan dan sanitasi makanan. Pengetahuan tentang gizi seimbang dan beragam diperlukan dalam menyusun menu sehari-hari, sehingga konsumen tercukupi kebutuhan gizi dan tidak bosan mengonsumsinya. Pengetahuan cara pengolahan pangan yang baik diperlukan dalam memilih cara-cara pengolahan yang tepat, pemilihan bahan baku dan bahan tambahan untuk menghasilkan makanan yang bergizi dan aman. Pengetahuan tentang keamanan pangan diperlukan untuk mengenali bahaya-bahaya dalam pangan dan menentukan cara pencegahannya. Pengetahuan tentang higiene perorangan dan sanitasi makanan diperlukan untuk mencegah masuknya bakteri dan bahan kimia berbahaya ke dalam pangan, serta sarana dan prasarana minimum yang harus dipenuhi oleh kantin untuk mewujudkan sarana kantin sehat.

Menurut Kementerian Kesehatan Dirjen PPPL (2013), bahwa Salah satu faktor untuk meningkatan derajat kesehatan masyarakat adalah pengelolaan makanan harus memenuhi syarat hygiene perorangan dan sanitasi makanan, sehingga upaya hygiene perorangan dan sanitasi makanan perlu dilakukan demi terciptanya kualitas makanan 
dikonsumsi aman dan terhindar dari penyakit. Untuk mengendalikan faktor risiko terjadinya kontaminasi terhadap makanan, baik yang berasal dari bahan makanan, orang, tempat, dan peralatan agar makanan tersebut aman dikonsumsi, pemerintah melaksanakan program Higiene Sanitasi Pangan (HSP). Keberhasilan program Higiene Sanitasi Pangan adalah menurunnya angka kejadian luar biasa keracunan makanan Higiene Sanitasi dapat ditingkatkan melalui intervensi terhadap penjamah makanan dengan tujuan meningkatkan pengetahuan dan sikap penjamah dalam pengelolaan makanan yang higienis.Kasus keracunan makanan cukup banyak terjadi di Indonesia. Pada tahun 2014 Badan Pengawasan Obat dan Makanan (BPOM) menginformasikan telah terjadi 43 kasus insiden keracunan makanan di berbagai wilayah Indonesia. Salah satu kejadian keracunan makanan disebabkan oleh pangan jajanan sebanyak 15 insiden keracunan dengan jumlah korban 468 orang serta 1 insiden keracunan akibat jasa boga dengan jumlah korban 748 orang. Berdasarkan penelitian yang dilakukan oleh Irawati (2012) menunjukan bahwa terdapat 52,8 persen makanan di kantin Universitas X Depok terkontaminasi oleh bakteri Escherichia Coli di sebabkan oleh kurangnya pengetahuan personal hygiene penjamah makanan dan faktor lainnya.

Higiene perorangan yaitu upaya kesehatan dengan cara memelihara dan melindungi kebersihan subjeknya. Hygiene perorangan membahas tentang cara menjaga kebersihan diri dan persyaratan performansi seorang pengolah dan pelayan makanan. Aspek hygiene perorangan dalam pengelolaan makanan berkaitan dengan kebersihan diri pengelola yang mencakup semua segi kebersihan diri pribadi pengelola kantin meliputi mandi secara teratur, mencuci tangan dengan seksama menggunakan sabun dan air bersih, merawat kuku tetap pendek dan menjaga kuku tetap bersih, dan selalu menggunakan peralatan memasak seperti celemek, memakai penutup kepala saat mengelola makanan. Sanitasi makanan adalah suatu upaya melindungi kebersihan lingkungan dari subjeknya, meliputi sanitasi pengolahan makanan, sanitasi peralatan pengolahan makanan dan bangunan pengolahan makanan. Beberapa metode yang dapat dilakukan untuk memengaruhi pengetahuan pengelola kantin melalui promosi kesehatan (8).

Promosi kesehatan merupakan upaya yang dilakukan terhadap masyarakat sehingga mereka mau dan mampu untuk memelihara dan meningkatkan kesehatan mereka sendiri (9). Promosi kesehatan didukung dengan beberapa media. Media promosi kesehatan yaitu semua upaya untuk menampilkan pesan atau informasi yang ingin disampaikan oleh komunikator baik melalui media cetak, elektronik dan media luar ruangan. Beberapa pendukung tersebut bisa diterapkan dengan ceramah dan penayangan video (10).

Universitas Pembangunan Nasional "Veteran" Jakarta memiliki kantin berjumlah 32 kantin yang terbagi antara 24 di kampus Pondok Labu dan 8 di kampus Limo, berdasarkan observasi awal peneliti masih terdapat kantin yang tidak menerapkan hygiene perorangan dan sanitasi makanan yang baik, contohnya pada saat menyajikan makanan secara bersamaan juga memegang peralatan pengolahan makanan yang kotor, pengelola kantin tidak mencuci tangan setelah memegang uang dari konsumen, tidak memakai peralatan untuk memasak seperti celemek, penutup kepala dan ada beberapa pengelola yang sedang menangani makanan kemudian bersin atau batuk, pengelola tersebut tidak menutup mulutnya. Hasil dari observasi awal peneliti menyimpulkan bahwa pengelola kantin UPN "Veteran" Jakarta perlu diberikan pengetahuan mengenai kantin sehat yang meliputi hygiene perorangan, sanitasi makanan dan menu gizi seimbang berupa pemberian promosi kesehatan melalui penyuluhan menggunakan metode ceramah dengan bantuan media elektronik berupa penanyangan video mengenai perilaku hidup bersih dan sehat.

Penyuluhan adalah kegiatan pendidikan yang dilakukan dengan cara menyebarkan pesan, menanamkan keyakinan sehingga masyarakat tidak saja sadar, tahu dan mengerti, tetapi juga mau dan bisa melakukan suatu ajuran yang ada hubungan dengan kesehatan (11). Metode ceramah merupakan penyampaian informasi dan pengetahuan secara lisan kepada objek yang ingin di berikan pesan dengan menggunakan alat bantu atau media dalam penyampaian pesan. Berdasarkan latar belakang dari data yang ada serta hasil pengamatan awal peneliti, maka peneliti ingin 
mengkaji mengenai pengaruh promosi kesehatan terhadap peningkatan pengetahuan pengelola kantin sehat di UPN "Veteran" Jakarta Tahun 2018. Penelitian ini bertujuan untuk menilai pengaruh promosi kesehatan terhadap peningkatan pengetahuan kantin sehat yang meliputi hygiene perorangan, sanitasi makanan dan gizi seimbang pengelola kantin di UPN "Veteran" Jakarta.

\section{METODE}

Desain penelitian ini adalah pendekatan kuantitatif jenis pra experimental dengan rancangan one group pre test and post test design. Alasan pemilihan desian penelitian ini dikarenakan peneliti bertujuan untuk mengetahui perbedaan dari pengetahuan, sikap dan perilaku penjamah makanan mengenai higiene sanitasi makanan sebelum dan sesudah dilakukannya intervensi. Penelitian ini dilakukan pada Bulan September 2017 di Kampus UPN Veteran Jakarta. Populasi dalam penelitian ini adalah seluruh pengelola kantin di UPN "Veteran" Jakarta dengan populasi 32 responden. Sampel yang diambil adalah total sampling. Analisis data yang digunakan dalam penelitian ini adalah statistic parametric untuk membuktikan ada atau tidaknya hubungan bermakna antara variabel independen dengan variabel dependen. Untuk melihat perbedaan hasil pengukuran awal (pre test) dengan pengukuran akhir (post test), maka dilakukan analisis menggunakan uji paired t test.

\section{HASIL DAN PEMBAHASAN}

Hasil penelitian menunjukan karakteristik responden yang telah dikumpulkan dan dilakukan uji univariat (distribusi frekuensi) di dalam penelitian ini meliputi umur, jenis kelamin, pendidikan dan lama kerjaresponden. Hasil pengumpulan data karakteristik responden hanya dilakukan satu kali yaitu sebelum diberikannya intervensi (pretest), karena pengujian setelah intervensi (posttest) dilakukan kepada responden yang sama dan responden yang dimaksud telah menyetujui untuk dilakukan pengambilan data untuk kedua kalinya.

Penelitian terlihat bahwa 100\% gambaran umur responden berada pada produktif (15-64 tahun). Gambaran jenis kelamin responden menunjukan jumlah terbanyak yaitu 25 reponden $(78,1 \%)$ pada perempuan.

Gambaran pendidikan responden menunjukan tingkat SMP terbanyak 11 responden $(32,4 \%)$. Gambaran lama kerja pengelola kantin yang terbanyak adalah $\geq 5$ tahun dengan jumlah 19 responden $(59,4 \%)$. Hasil penelitian menunjukan hubungan atau pengaruh dari tiap variabel yang dilakukan pengujian, variabel yang dilakukan pengujian adalah variabel total pengetahuan kantin sehat sebelum dan sesudah intervensi, total pengetahuan higiene perorangan sebelum dan sesudah intervensi, total pengetahuan sanitasi makanan sebelum dan sesudah intervensi, dan pengetahuan gizi seimbang sebelum dan sesudah intervensi.

Hasil penelitian ini menunjukan bahwa promosi kesehatan melalui penyuluhan dengan metode ceramah dan media penayangan video dapat memengaruhi dimensi pengetahuan kantin sehat ditunjukan dengan nilai $p$ value $=$ 0,000 dengan rata-rata pengetahuan sebelum promosi kesehatan yaitu 1,00 dan sesudah promosi kesehatan yaitu 2,00 . Terdapat perbedaan nilai pengetahuan sebelum dan sesudah promosi kesehatan yaitu tentang kantin sehat pada pengelola kantin di UPN "Veteran" Jakarta. Serta Hasil nilai p value yang bernilai 0,000. Hal ini menunjukan adanya pengaruh promosi kesehatan terhadap peningkatan pengetahuan kantin sehat pada pengelola kantin di UPN "Veteran" Jakarta. Dari intervensi yang diberikan oleh peneliti dapat mengubah pengetahuan pengelola kantin tentang kantin sehat diharapkan mampu merubah sikap serta perilaku yang sesuai dengan penjamah kantin yang sehat.

Hasil penelitian ini menunjukan bahwa promosi kesehatan melalui penyuluhan dengan metode ceramah dan media penayangan video dapat memengaruhi dimensi pengetahuan higiene perorangan ditunjukan dengan nilai $\mathrm{p}$ value $=0,008$ dengan rata-rata pengetahuan sebelum promosi kesehatan yaitu 1,78 dan sesudah promosi kesehatan 
yaitu 2,00. Terdapat perbedaan nilai pengetahuan sebelum dan sesudah promosi kesehatan tentang higiene perorangan pada pengelola kantin di UPN "Veteran" Jakarta. Hal ini ditunjukan melalui hasil yang diberikan dari hasil uji bivariat (Uji Wilcoxon) yang dilakukan terhadap variabel pengetahuan higiene Peroranganserta Hasil nilai $p$ value yang bernilai 0,008 . Hal ini menunjukan adanya pengaruh promosi kesehatan terhadap peningkatan pengetahuan higiene perorangan pada pengelola kantin di UPN "Veteran" Jakarta.

Hasil penelitian ini menunjukan bahwa promosi kesehatan melalui penyuluhan dengan metode ceramah dan media penayangan video dapat memengaruhi dimensi pengetahuan sanitasi makanan ditunjukan dengan nilai $\mathrm{p}$ value $=0,014$ dengan rata-rata pengetahuan sebelum promosi kesehatan yaitu 1,81 dan sesudah promosi kesehatan yaitu 2,00. Terdapat perbedaan nilai pengetahuan sebelum dan sesudah promosi kesehatan tentang sanitasi makanan pada pengelola kantin di UPN "Veteran" Jakarta. Hal ini ditunjukan melalui hasil yang diberikan dari hasil uji bivariat (Uji Wilcoxon) yang dilakukan terhadap variabel pengetahuan sanitasi makananserta hasil nilai $\mathrm{p}$ value yang bernilai 0,014. Hal ini menunjukan adanya pengaruh promosi kesehatan terhadap peningkatan pengetahuan sanitasi makanan pada pengelola kantin di UPN "Veteran" Jakarta.

Hasil penelitian ini menunjukan bahwa promosi kesehatan melalui penyuluhan dengan metode ceramah dan media penayangan video dapat memengaruhi dimensi pengetahuan gizi seimbang ditunjukan dengan nilai $\mathrm{p}$ value $=$ 0,003 dengan rata-rata pengetahuan sebelum promosi kesehatan yaitu 1,72 dan sesudah promosi kesehatan yaitu 2,00. Terdapat perbedaan nilai pengetahuan sebelum dan sesudah promosi kesehatan gizi seimbang pada pengelola kantin di UPN "Veteran" Jakarta. Hal ini ditunjukan melalui hasil yang diberikan dari hasil uji bivariat (Uji Wilcoxon) yang dilakukan terhadap variabel pengetahuan gizi seimbang serta hasil nilai p value yang bernilai 0,003 . Hal ini menunjukan adanya pengaruh promosi kesehatan terhadap peningkatan pengetahuan gizi seimbang pada pengelola kantin di UPN "Veteran" Jakarta.

Hasil penelitian terkait dengan umur sejalan dengan penelitian Susilawati (2012) bahwa sebagian besar pekerja kantin di kampus IPB Dramaga berumur 16-65 tahun. menunjukkan bahwa semakin tinggi umur pekerja kantin maka tingkat pengetahuannya terhadap higiene dan sanitasi semakin baik (11). Jumlah pekerja kantin perempuan lebih besar dari pekerja kantin laki-laki. Menurut Ely Agustina (2006) menyatakan bahwa ada hubungan antara pendidikan dengan praktik hygiene dan sanitasi (12). Menurut Suhardjo (2009), pengalaman kerja seseorang dapat mencerminkan kemampuan dan kesiapan seseorang dalam suatu bidang pekerjaan (13).

Menurut Kemenkes (2015), Kantin sehat adalah kantin yang memenuhi syarat hygiene peroarangan, sanitasi makanan dan gizi seimbang yang baik. Kantin termasuk dari tempat pengolahan makanan, dimana harus memenuhi syarat kesehatan yang memenuhi persyaratan higiene dan sanitasi yang baik (14). Hasil penelitian ini sesuai dengan yang dikemukakan Andry Hartono (2005) yang mengemukakan bahwa semakin baik pengetahuan tentang higiene perorangan maka semakin kecil kemungkinan terjadinya kontaminasi makanan yang terjadi dikantin (15).

Hasil penelitian ini sesuai dengan penelitian yang dilakukan oleh Budiyono (2008) menyatakan bahwa ada hubungan antara pengetahuan penjamah makanan dengan pengetahuan sanitasi makanan (16). Penelitian ini sejalan dengan Maifo (2016) dengan hasil penelitian menunjukan bahwa terdapat hubungan yang positif dan signifikan antara pengetahuan gizi seimbang dan konsumsi KFC pada mahasiswa pendidikan tata boga UNP sebesar 24,9\% (17).

\section{KESIMPULAN}

Penelitian yang telah penulis lakukan memiliki tujuan untuk menilai pengaruh promosi kesehatan terhadap peningkatan pengetahuan pengelola kantin tentang kantin sehat yang meliputi pengetahuan higiene perorangan, sanitasi makanan, dan gizi seimbang pada pengelola kantin di UPN "Veteran" Jakarta. Kesimpulan yang dihasilkan da- 
lam penelitian ini adalah ada perbedaan nilai pengetahuan sebelum dan sesudah intervensi. Pengetahuan antara sebelum intervensi sehingga ada pengaruh promosi kesehatan terhadap peningkatan pengetahuan pengelola kantin sehat di UPN "Veteran" Jakarta. Perbedaan bermakna tersebut menunjukan adanya pengaruh dari intervensi promosi kesehatan yang diberikan oleh peneliti kepada pengelola kantin di UPN "Veteran Jakarta. Kesimpulannya yaitu terdapat pengaruh promosi kesehatan terhadap peningkatan pengetahuan pengelola kantin yang meliputi kantin sehat, hygiene perorangan, sanitasi makanan, dan gizi seimbang.

\section{DAFTAR PUSTAKA}

1. Sunjaya, dkk 2009, Pembinaan Pedagang Makanan Kaki Lima Untu Meningkatkan Higiene Dan Sanitasi Pengolahan Dan Penyediaan Makanan Di Desa Penatih Denpasar Timur. PS IKM Universitas Udayana (Online).

2. Gubernur Provinsi Daerah Ibu Kota 2013, Peraturan Gubernur Nomor 140 Tentang Standar Penyelenggaraan Kantin Sekolah Sehat.

3. Budiwati, 2013, Sanitasi, Higiene dan Keselamatan Kerja Bidang Makanan 1.

4. Maulana, HDJ 2009, Hubungan Pengetahuan Gizi

5. Badan Pengawasan Obat dan Makanan 2012, Ke manan Pangan di Kantin Sekolah.

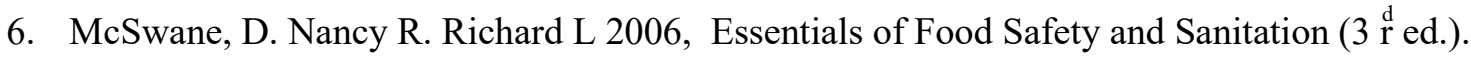

7. Adhisty, Z 2014, Penilaian Kantin Sehat Pangan Jajanan Anak Sekolah di KotaDepok. Institut Pertanian Bogor.

8. Badan Pengawasan Obat dan Makanan 2014, Keamanan Pangan di Kantin Sekolah.

9. Notoatmodjo, S 2014, Metodologi Penelitian Kesehatan, Rineka Cipta, Jakarta

10. Astuti, E 2012, Studi Komparasi Promosi Kesehatan Antara Simulasi Dan Penayangan Video Terhadap Perilaku Personal Hygiene Anak Usia Sekolah Di SDN Kaliduren Moyudan Sleman Yogyakarta, Sekolah Tinggi Ilmu Kesehatan 'Aisyiyah, Yogyakarta.

11. Susilawati 2012, Gambaran Higiene Personal Pekerja Kantin di Kampus IPB Dramaga Melalui Pengujian Staphylococcus aureus, Bogor.

12. Ely Agustina, 2006, Faktor-faktor yang berhubungan dengan praktik higiene sanitasi tenaga penjamah makanan di instalasi gizi RSUD Unit Swadana kudus.

13. Suhardjo 2009, Sosio Budaya Gizi, Institut Pertanian Bogor.

14. Kementrian Kesehatan Nomor 1098/Menkes/SK/VII/2003, Tentang Persyaratan Higiene Sanitasi Rumah Makan dan Restoran

15. Andry Hartono 2005, Penyakit Bawaan Makanan, Penerbit EGC, Jakarta.

16. Budiyono, 2008, Tingkat Pengetahuan dan Praktik Penjamah Makanan Tentang Higiene dan Sanitasi Makanan pada Warung Makan di Tembalang Kota Semarang Tahun 2009.

17. Maifo,L, 2016, Hubungan Pengetahuan Gizi dengan Konsumsi KFC Mahasiswa Pendidikan Tata Boga, Universitas Negeri Padang Tahun 2016. 